\title{
Performance of disposable endoscopic forceps ac- cording to the manufacturing techniques
}

\author{
Chang-Il Kwon ${ }^{1,}$, Gwangil Kim ${ }^{2,}$, Jong Pil Moon ${ }^{3}$, Ho Yun ${ }^{3}$, Weon Jin $\mathrm{Ko}^{1}$, Joo Young Cho ${ }^{1}$, and \\ Sung Pyo Hong ${ }^{1}$
}

${ }^{1}$ Digestive Disease Center, ${ }^{2}$ Department of Pathology, CHA Bundang Medical Center, CHA University, Seongnam; IInterventional Research Center, M.I. Tech Co. Ltd., Pyeongtaek, Korea
Background/Aims: Recently, to lower the production costs and risk of infection, new disposable biopsy forceps made using simple manufacturing techniques have been introduced. However, the effects of the manufacturing techniques are unclear. The aim of this study was to evaluate which types of biopsy forceps could obtain good-quality specimens according to the manufacturing techniques.

Methods: By using an in vitro nitrile glove popping model, we compared the popping ability among eight different disposable biopsy forceps (one pair of biopsy forceps with cups made by a cutting method [cutting forceps], four pairs of biopsy forceps with cups made by a pressing method [pressing forceps], and three pairs of biopsy forceps with cups made using a injection molding method [molding forceps]). Using an in vivo swine model, we compared the penetration depth and quality of specimen among the biopsy forceps.

Results: In the in vitro model, the molding forceps provided a significantly higher popping rate than the other forceps (cutting forceps, 25.0\%; pressing forceps, 17.5\%; and molding forceps, $41.7 \%$; $p=0.006$ ). In the in vivo model, the cutting and pressing forceps did not provide larger specimens, deeper biopsy specimen, and higher specimen adequacy than those obtained using the molding forceps ( $p=0.2631, p=0.5875$, and $p=0.2147$, respectively). However, the molding forceps showed significantly more common crush artifact than the others (cutting forceps, $0 \%$; pressing forceps, 5.0\%; and molding forceps, $43.3 \%$; $p=0.0007$ ).

Conclusions: The molding forceps provided lower performance than the cutting and pressing forceps in terms of crush artifact.

Keywords: Biopsy; Instruments; Endoscopy; Disposable equipment

\section{INTRODUCTION}

In the field of gastrointestinal endoscopy, the development of new devices and related programs has led to the advancement of diagnostic methods at an exponential rate, but direct histopathological examination is still the most important and accurate diagnostic method. Therefore, the quality of endoscopic biopsy specimen is crucial for a successful histological diagnosis. The basic concept of biopsy forceps has not changed much, but various types of biopsy forceps with different designs and materials are widely used [1]. Previous reports indicated that the quality of biopsy specimens depends on the shape and size of the forceps cups [2-5]. However, as endoscopes are becoming slimmer, smaller-sized cups have become more widely used, since larger-sized cups limit the diameter of the working channel. This resulted in technological advancements, including changing the 
shape of cups from oval to elongated shape, processing the edges of cups in a serrated or toothed-jaw cutting shape, or inserting a stabilizing needle or spike between cups, using more precise processing methods [1].

Meanwhile, with reports indicating cross-contamination and spread of infection by endoscopic accessories, the reusable biopsy forceps have been replaced by the disposable ones [6-8]. However, the replacement process was not easy because of the fixed insurance payment system in some countries. There have been even some cases where disposable biopsy forceps were reprocessed to be reused several times as an interim measure. The biggest technical issue regarding reusing disposable biopsy forceps is that it can cause deformation of the forceps, not to mention cross-contamination. Unlike reusable biopsy forceps, which are made to endure exposure to sterilants or disinfectants, disposable biopsy forceps are easily changed or deformed when damaged by reprocessing. As such, the working channel of the endoscope can be damaged, which would incur high repair costs or various unexpected problems in biopsy sampling. To resolve these issues, disposable biopsy forceps with lower production costs were required to overcome the limitations of the insurance payment system. Many countries, including the United States, used this method until 2000, when the change was triggered by the U.S. Food and Drug Administration during the presentation of a guideline to regulate single-use devices. Currently, professional companies are commissioned to perform a more thorough reprocessing, or cheaper disposable biopsy forceps are used only once and then discarded $[9,10]$.

The disposable biopsy forceps do not have more functional problems than the reusable ones, but they do have various types of technical issues affecting cost-effectiveness. To reduce the production costs, either less costly methods could be used instead of precision manufacturing methods for reusable biopsy forceps, or low-priced materials instead of main materials could be used. The most essential problem in terms of the technical aspects or production costs is the cup portion that catches and obtains specimens. As one of the manufacturing methods of this cup portion, the injection molding method has become widely used. It has a very short processing time and a capability of mass production, with lead to cheap prices. However, these low-priced disposable bi- opsy forceps are currently being widely used without a proper evaluation of the quality of specimens obtained, biopsy performance, and complication rate in comparison with the other types of forceps.

The first aim of this study was to evaluate which types of disposable biopsy forceps could obtain better-quality specimens according to the manufacturing techniques, including the injection molding method. The second aim was to identify which test could be used to accurately evaluate the performance of biopsy forceps.

\section{METHODS}

An in vitro nitrile glove popping model and an in vivo swine model were used to compare performance among different disposable biopsy forceps in this proof-of-concept study. The animal study was approved by the Institutional Animal Care Committee of Medi Kinetics Co. Ltd. (Pyeongtaek, Korea), a contract research organization for pre-clinical testing, prior to its commencement of this study (MK-IACUC \# 160919-001).

\section{Materials}

The manufacturing techniques for the cup portion of disposable biopsy forceps are classified into three types as shown in Fig. 1. First, the cutting method using precision lathe technique (cutting forceps hereinafter) uses a lathe to precisely cut or process metals. For this reason, the cups have the smoothest surface, and good finishing make them the most superior in terms of tolerance factor. In addition, their design can be changed freely, facilitating improvement. However, the cutting forceps have the highest processing and production costs, and the lowest productivity among the three methods. Second, the pressing method used the press molding technique (pressing forceps hereinafter), which includes bending or folding thin metal boards. Compared with the cutting forceps, they have a superior productivity, lower production costs, and non-inferior tolerance factor. On the other hand, owing to the limitation in precise design, it has a lower degree of precision and makes a change in the design more difficult than that of the cutting method. Third, the cheapest method using the injection molding process (molding forceps hereinafter) makes a specific shape by applying heat to metal powder 


\begin{tabular}{|c|c|c|c|}
\hline Manufacturing techniques & Cutting forceps & Pressing forceps & Molding forceps \\
\hline $\begin{array}{l}\text { Samples of } \\
\text { cups area }\end{array}$ & & & \\
\hline Characteristics & $\begin{array}{l}\text { - Precise processing by } \\
\text { a precision lathe }\end{array}$ & $\begin{array}{l}\text { - Press technique with a thin } \\
\text { metal board (red circles) }\end{array}$ & $\begin{array}{l}\text { - Injection molding process } \\
\text { with metal powder }\end{array}$ \\
\hline Advantage & $\begin{array}{l}\text { - Smooth surface (red circle) } \\
\text { - Minimal tolerance factor }\end{array}$ & $\begin{array}{l}\text { - Relatively high productivity } \\
\text { - Relatively low production costs }\end{array}$ & $\begin{array}{l}\text { - Highest productivity } \\
\text { - Lowest production costs }\end{array}$ \\
\hline Disadvantage & $\begin{array}{l}\text { - High production costs } \\
\text { - Low productivity }\end{array}$ & $\begin{array}{l}\text { - Lower degree of precision } \\
\text { - Limitation of modification }\end{array}$ & $\begin{array}{l}\text { - Rough surface } \\
\text { - Ejector pin mark (red circle) } \\
\text { - High error rate in producing }\end{array}$ \\
\hline
\end{tabular}

Figure 1. Characteristics of disposable biopsy forceps according to the manufacturing techniques. Cutting forceps, made using a precision lathe technique, are characterized by the smoothest surface and the best finishing. Pressing forceps, made of a thin metal board with a press molding technique, are characterized by higher productivity and lower production cost than cutting forceps. Molding forceps, made with an injection molding process, are characterized by the highest productivity and lowest production cost. However, it has a coarse surface and crude design. Red circles present the typical characteristic areas of each type.

in a designated mold. Having the most superior productivity among the three methods, it can be mass-produced at a very low cost. However, it has a very coarse metal surface, crude design, and the possibility of having an ejector pin mark left while removing it from the mold. It also has a very high error rate in production and a very low degree of precision. A secondary precise surface finishing can be performed to obtain better quality, but not to avoid an increase in the production costs.

Generally, the cost of producing the cups of the cutting forceps is approximately 10 times more than that of the other two methods. The costs per unit of the cups of the pressing and molding forceps are almost same. However, the two methods require mold making, which costs twice more for the pressing forceps than for the molding forceps. In addition, in the lifetime of the mold of the pressing forceps, bending or the folding thin metal boards can easily induce stress to the mold. Therefore, pressing forceps require more development/higher pro- duction costs because more-frequent mold replacement is needed than that for the molding forceps.

The following eight different disposable biopsy forceps with similar closed cup diameters (2.2 to $2.4 \mathrm{~mm}$ ) were evaluated: A, cutting forceps, FB-23oK, EndoJaw (Olympus Co., Tokyo, Japan); B, pressing forceps, Radial Jaw 4 (Boston Scientific Corp., Natick, MA, USA); C, pressing forceps, DBF-2.4-16o-S, Captura (Cook Medical Inc., Winston-Salem, NC, USA); D, molding forceps, BFO16oP, Endo-Upex (Upex-Med Corp., Anyang, Korea); E, molding forceps, FM-EFooo3, ClearBite (Finemedix Co. Ltd., Daegu, Korea); F, pressing forceps, BIO1-C4-23-18o, EndoBite (Medwork GmbH, Aisch, Germany); G, pressing forceps, IC-FCN23S, Core-Forceps (Incore Co. Ltd., Seoul, Korea); and H, molding forceps, BF16o, Optimos (Taewoong Medical Co. Ltd., Gimpo, Korea). The characteristics of the different forceps models are presented in Table 1. 
Table 1. Characteristics of eight models of biopsy forceps used in the evaluation of performance according to the manufacturing techniques

\begin{tabular}{|c|c|c|c|c|c|c|c|c|}
\hline Forceps model & A & B & $\mathrm{C}$ & $\mathrm{D}$ & E & $\mathrm{F}$ & G & $\mathrm{H}$ \\
\hline Producer & Olympus & $\begin{array}{l}\text { Boston } \\
\text { Scientific }\end{array}$ & $\begin{array}{l}\text { Cook Med- } \\
\text { ical }\end{array}$ & Upex-Med & Finemedix & Medwork & Incore & $\begin{array}{l}\text { Taewoong } \\
\text { Medical }\end{array}$ \\
\hline Model type & FB-23oK & $\begin{array}{l}\text { Radial Jaw } \\
4\end{array}$ & $\begin{array}{l}\mathrm{DBF}-2.4- \\
160-\mathrm{S}\end{array}$ & $\mathrm{BFO}_{160 \mathrm{P}}$ & $\begin{array}{l}\text { FM- } \\
\text { EFooo3 }\end{array}$ & $\begin{array}{l}\mathrm{BIO}_{1}-\mathrm{C}_{4}- \\
23-180\end{array}$ & IC-FCN23S & $\mathrm{BF} 160$ \\
\hline Location of producer & Japan & USA & USA & Korea & Korea & Germany & Korea & Korea \\
\hline Location of factory & Japan & Costa Rica & USA & Korea & China & China & Korea & China \\
\hline $\begin{array}{l}\text { Manufacturing } \\
\text { method }\end{array}$ & Cutting & Pressing & Pressing & Molding & Molding & Pressing & Pressing & Molding \\
\hline Cup size, mm & 2.3 & 2.2 & 2.4 & 2.3 & 2.3 & 2.3 & 2.3 & 2.4 \\
\hline
\end{tabular}

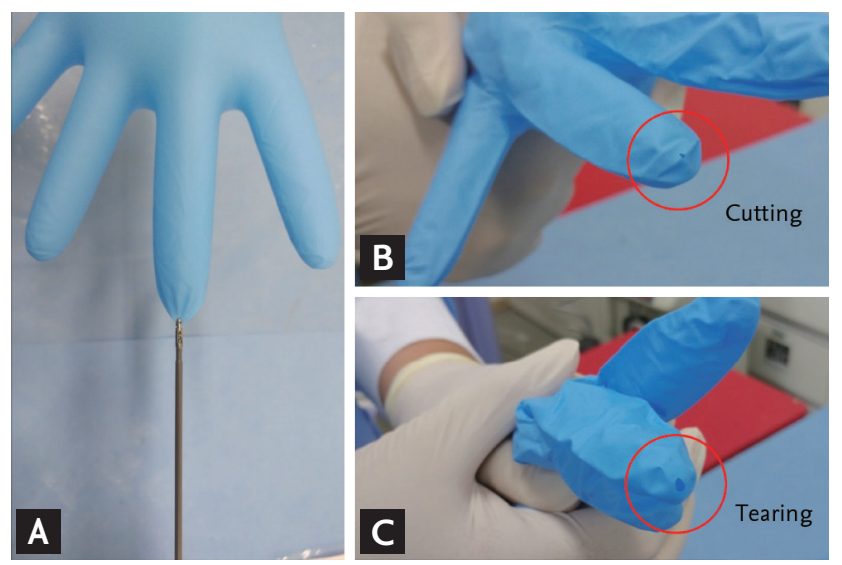

Figure 2. In vitro nitrile glove popping test. (A) The tip of air-filled nitrile glove, which are put on during endoscopic examination, is grasped and pulled with biopsy forceps to see if there is any popping. The popping occurs by two phenomena as follows: the cutting phenomenon, where only the part grasped inside the cups of the biopsy forceps is sharply cut (B), and the tearing phenomenon, where not only the part grasped inside the cups but also the surrounding areas are torn (C).

\section{In vivo nitrile glove popping test}

This is a commonly used test to determine the grasping ability of biopsy forceps. The tips of air-filled nitrile gloves (Nitrisoft, Kossan Latex Industries Sdn. Bhd., Klang, Malaysia), which are used during endoscopic examination, were grasped and pulled with biopsy forceps to determine if there was any cutting or tearing of the gloves (Fig. 2). Cutting and tearing are not generally distinguished when assessing grasping ability, but the cutting phenomenon refers to popping with a sharp cut of the part grasped inside the cups of the biopsy forceps, while tearing phenomenon refers to popping with a large tear of the surrounding areas and not just a cut of the part grasped inside the cups. These two are not accurately distinguishable, and a better test result is not necessarily indicative of a better grasping ability, which is one weakness of the test. Furthermore, cups with smoothly processed surface may be slippery when attempting to grasp the gloves and thus may not create any popping. This is a very simple, widely used method, but determining whether it can successfully access the performance of biopsy forceps is highly important. Thus, this test was included in this study to determine its objective accuracy. Using four biopsy forceps of each type, 20 popping tests, five times for each forceps, were performed. The biopsy forceps were tested in a random order by a tester (W.J.K.) who was blinded to the type of the biopsy forceps.

\section{In vivo swine study}

Two mini-pigs (Sus scrofa; mean age, 14 months; mean body weight, $30.2 \mathrm{~kg}$ ) were used for the in vivo swine study. Before this study, the pigs were fasted for $>24$ hours, except for water given ad libitum. The pigs were pre-sedated using an intramuscular injection of atropine sulfate $(0.04 \mathrm{mg} / \mathrm{kg})$, xylazine $(2 \mathrm{mg} / \mathrm{kg})$, and tiletamine-zolazepam $(5 \mathrm{mg} / \mathrm{kg})$. Then, the pigs were intubated, and general anesthesia was achieved using $0.5 \%$ to $2 \%$ isoflurane through the endotracheal tube with $70 \%$ nitrous oxide and 30\% oxygen provided by a ventilator. For endoscopic examination, the pigs were placed on their left lateral sides on a table.

Using a forward endoscope (GIF-Q260J, Olympus Co.), an expert endoscopist (W.J.K.) who was blinded to 

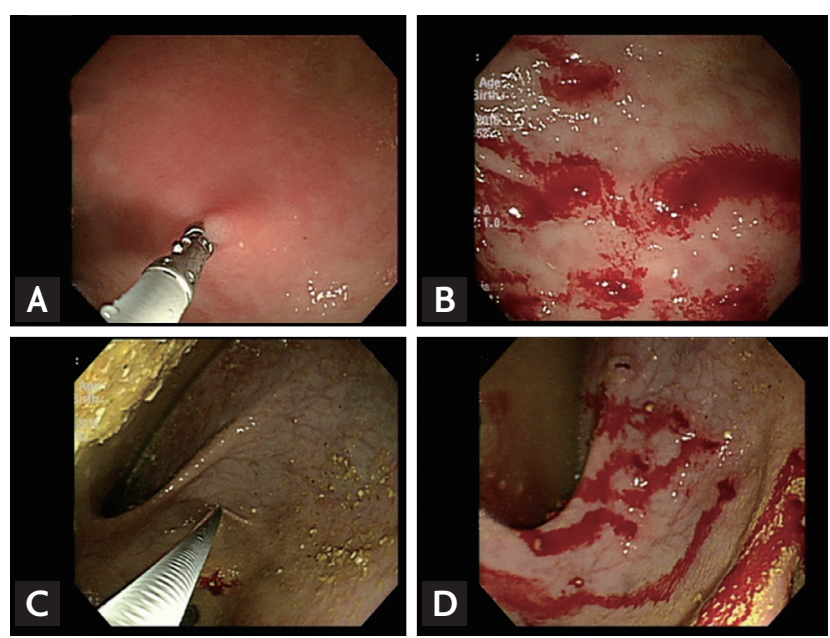

Figure 3. Endoscopic examination with biopsy samplings. Five specimens were obtained from the greater curvature side of the antrum in one swine (A, B), and five specimens were obtained from the opposite lesser curvature side of the antrum in the other swine (C, D).

the type of the biopsy forceps performed the endoscopic examination with biopsy sampling. Using two pairs of biopsy forceps of each type, five specimens were obtained from the greater curvature side of the antrum in one swine and five specimens from the opposite lesser curvature side of the antrum in the other swine (Fig. 3).

\section{Histopathological examination}

All biopsy specimens were examined by an experienced gastrointestinal pathologist (G.K.) who was blinded to the type of the biopsy forceps tested. Each specimen was analyzed for maximal diameter (measured in millimeter), depth of acquired specimen (lamina propria, muscularis mucosa, or submucosa), adequacy for diagnosis (adequate or inadequate; general adequacy of the specimens for diagnosis by the experienced gastrointestinal pathologist), and crush artifact (none, mild, moderate, or severe; severe crush artifact can affect the diagnosis) (Fig. 4) [5].

The same technique was used for the preparation of the histology slides for tissues obtained by all forceps. The best specimen from each set was used for statistical analysis. Specimens were fixed with 10\% neutral-buffered formalin and processed routinely in a Thermo Shandon Exelsior ES tissue processor (Thermo Fisher Scientific, Waltham, MI, USA). Paraffin-embedded tissues were sectioned on a microtome at $4 \mu \mathrm{m}$ and mount-

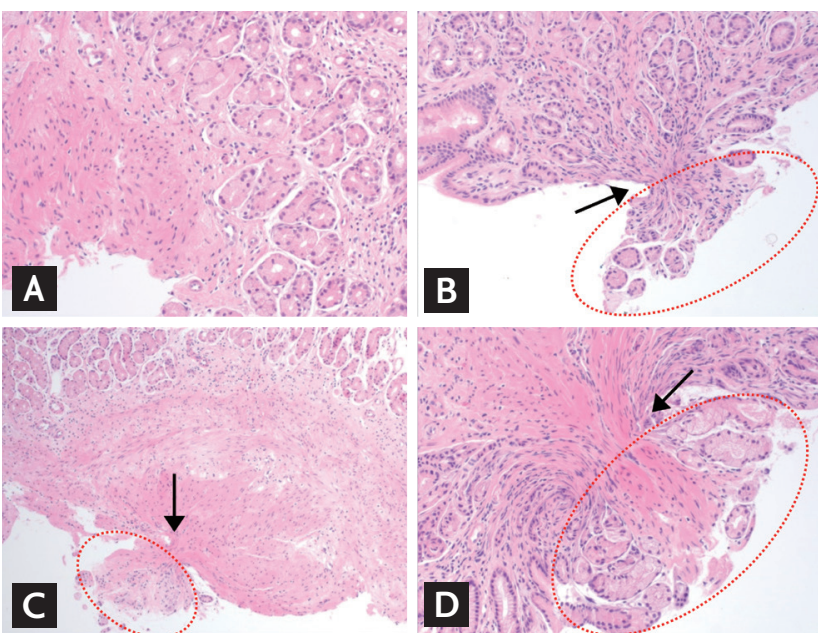

Figure 4. Representative images of crush artifacts classified as grade $\mathrm{o}$ to $3(\mathrm{H} \& \mathrm{E}, \times 200)$. (A) Grade o, no crush artifact; (B) grade 1 , mild crush artifact; (C, D) grade 2, moderate crush artifact; and grade 3, severe crush artifact that can affect diagnosis. The arrows present the compression areas that were used for classifying the degree of crush artifact, and red dot circles present the parts of tearing tissues.

ed on the glass slides for hematoxylin and eosin staining.

\section{Statistical analysis}

The mean \pm standard deviation (SD), and range were used to summarize the data for continuous variables and percentages for categorical variables. The Kruskal-Wallis test was used to analyze the difference of specimens between the groups. A $p$ value of $<0.05$ was considered significant. Statistical analysis was performed with the IBM SPSS Statistics version 21.0.0 software (IBM Co., Armonk, NY, USA).

\section{RESULTS}

\section{In vivo nitrile glove popping test}

Between the tested types of forceps, there was a significant difference in popping rate $(p<0.001)$. Type $\mathrm{D}$ (molding forceps) and type F forceps (pressing forceps) had dominant popping rates ( $85 \%$ and $55 \%$, respectively). Between the three types of manufacturing techniques, the molding forceps provided a significantly higher bursting rate than the other forceps (cutting forceps, 25.0\%; pressing forceps, 17.5\%; and molding forceps, 41.7\%; $p=0.006)$ (Table 2). 


\section{In vivo swine test}

A summary of the performance of different types of forceps according to the producing company is shown in Table 3. When comparing the specimen size, no significant difference was observed between the eight types of forceps $(p=0.5180$ ) (Fig. 5). In terms of the depth involvement, no significant difference was present (reaching \% to the muscularis mucosa or submucosa; $p=0.6431$ ). As for the specimen adequacy to enable examination for diagnosis, no significant difference was observed between the three types (\% of adequate specimens for diagnosis; $p$ $=0.5219)$. However, types $\mathrm{D}, \mathrm{E}$, and $\mathrm{H}$ had a significantly more common crush artifact than the others $(p=0.0030)$.

The summary of the results on the performance of different types of forceps according to the manufacturing techniques are shown in Table 4. In terms of specimen

Table 2. Results of in vitro nitrile glove popping test

\begin{tabular}{|c|c|c|c|c|}
\hline \multirow{2}{*}{ Forceps classification } & \multicolumn{2}{|c|}{ Nitril glove popping test } & \multirow{2}{*}{ Popped/total, \% } & \multirow{2}{*}{$p$ value } \\
\hline & Unpopped & Popped & & \\
\hline Company & & & & $<0.001$ \\
\hline A, Cutting & 15 & 5 & 25 & \\
\hline B, Pressing & 17 & 3 & 15 & \\
\hline C, Pressing & 20 & 0 & o & \\
\hline $\mathrm{D}$, Molding & 3 & 17 & 85 & \\
\hline E, Molding & 16 & 4 & 20 & \\
\hline F, Pressing & 9 & 11 & 55 & \\
\hline G, Pressing & 20 & $\mathrm{o}$ & 0 & \\
\hline H, Molding & 16 & 4 & 20 & \\
\hline Total & 116 & 44 & $27 \cdot 5$ & \\
\hline Manufacturing techniques & & & & 0.006 \\
\hline Cutting forceps & 15 & 5 & 25 & \\
\hline Pressing forceps & 66 & 14 & $17 \cdot 5$ & \\
\hline Molding forceps & 35 & 25 & 41.7 & \\
\hline Total & 116 & 44 & $27 \cdot 5$ & \\
\hline
\end{tabular}

Table 3. Results of forceps performance according to the company

\begin{tabular}{|c|c|c|c|c|c|c|c|c|c|}
\hline & $\begin{array}{c}\text { A } \\
(n=10)\end{array}$ & $\begin{array}{c}B \\
(n=10)\end{array}$ & $\begin{array}{c}C \\
(n=10)\end{array}$ & $\begin{array}{c}D \\
(n=10)\end{array}$ & $\begin{array}{c}E \\
(n=10)\end{array}$ & $\begin{array}{c}\mathrm{F} \\
(\mathrm{n}=10)\end{array}$ & $\begin{array}{c}\mathrm{G} \\
(\mathrm{n}=10)\end{array}$ & $\begin{array}{c}\mathrm{H} \\
(\mathrm{n}=10)\end{array}$ & $p$ value \\
\hline Specimen size, mm & $3.70 \pm 1.22$ & $3.85 \pm 1.44$ & $4.48 \pm 1.16$ & $3.48 \pm 0.53$ & $4.05 \pm 1.13$ & $4.24 \pm 1.09$ & $4.03 \pm 1.37$ & $3.85 \pm 0.91$ & 0.5180 \\
\hline Depth involvement & & & & & & & & & 0.6431 \\
\hline Lamina propria & 7 & 7 & 7 & 5 & 8 & 6 & 7 & 4 & \\
\hline $\begin{array}{l}\text { Muscularis mucosa } \\
\text { or submucosa }\end{array}$ & 3 & 3 & 3 & 5 & 2 & 4 & 3 & 6 & \\
\hline Specimen adequacy & 9 & 9 & 10 & 10 & 10 & 10 & 10 & 10 & 0.5219 \\
\hline Crush artifact & & & & & & & & & 0.0030 \\
\hline None & 10 & 10 & 9 & 5 & 7 & 10 & 9 & 5 & \\
\hline Mild & 0 & 0 & 1 & 4 & 3 & 0 & 1 & 5 & \\
\hline Moderate & o & ० & ० & 1 & o & $\mathrm{O}$ & $\mathrm{O}$ & $\mathrm{O}$ & \\
\hline Severe & 0 & 0 & 0 & o & o & 0 & 0 & 0 & \\
\hline
\end{tabular}

Values are presented as mean $\pm \mathrm{SD}$. 
size, no significant difference was observed between the three types (cutting forceps, $3.70 \pm 1.22 \mathrm{~mm}$; pressing forceps, $4.15 \pm 1.24 \mathrm{~mm}$; and molding forceps, $3.79 \pm$ $0.89 \mathrm{~mm} ; p=0.2631$ ) (Fig. 6). In terms of depth involvement, no significant difference was observed between the three groups (cutting forceps, 30\%; pressing forceps, 32.5\%; and molding forceps, $43.3 \%$; $p=0.5875$ ). In terms of specimen adequacy, no significant difference was observed between the three types (cutting forceps, 90\%; pressing forceps, $97.5 \%$; and molding forceps, 100\%; $p$ $=0.2147)$. However, the molding forceps had significant-

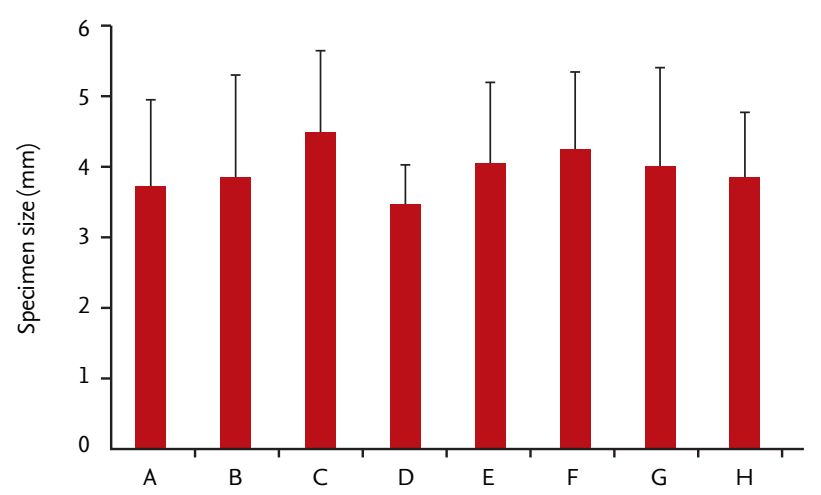

Figure 5. Comparison of specimen sizes according to manufacturing company. No significant difference was observed between the eight types of forceps $(p=0.5180)$ (A, cutting forceps, Olympus; B, pressing forceps, Boston Scientific; C, pressing forceps, Cook Medical; D, molding forceps, Upex-Med; E, molding forceps, Finemedix; F, pressing forceps, Medwork; G, pressing forceps, Incore; and $\mathrm{H}$, molding forceps, Taewoong Medical). ly more common crush artifact than the other forceps (cutting forceps, $\% \%$; pressing forceps, 5.0\%; and molding forceps, $43.3 \% ; p=0.0007$ ).

\section{DISCUSSION}

When disposable biopsy forceps share a similar shape and size of cups as those of reusable biopsy forceps, they are known to have similar performance in terms of specimen size, histological depth, and so forth [11]. The

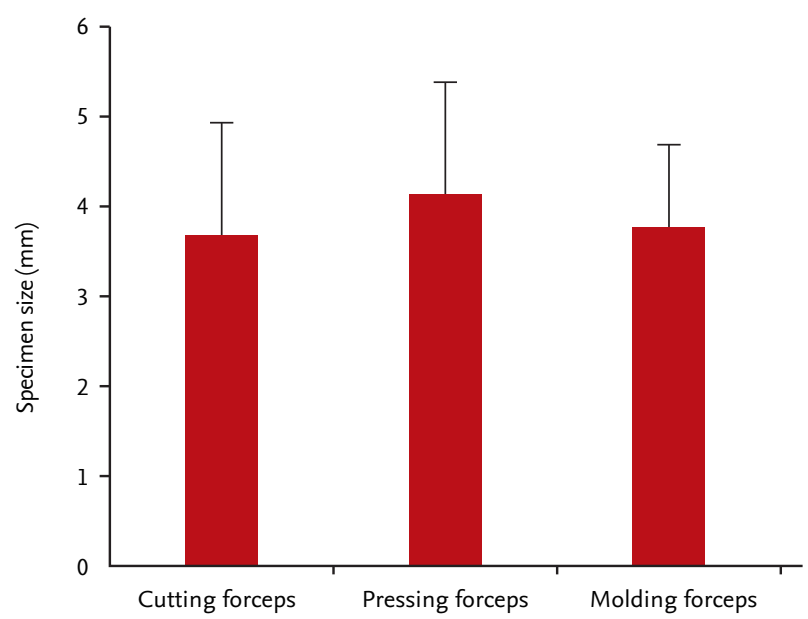

Figure 6. Comparison of specimen sizes according to manufacturing technique. No significant difference was observed between the three groups $(p=0.2631)$.

Table 4. Results of forceps performance according to the manufacturing techniques

\begin{tabular}{|c|c|c|c|c|}
\hline Variable & $\begin{array}{l}\text { Cutting forceps } \\
\qquad(\mathrm{n}=10)\end{array}$ & $\begin{array}{l}\text { Pressing forceps } \\
\qquad(\mathrm{n}=40)\end{array}$ & $\begin{array}{l}\text { Molding forceps } \\
\qquad(\mathrm{n}=30)\end{array}$ & $p$ value \\
\hline Specimen size, $\mathrm{mm}$ & $3.70 \pm 1.22$ & $4.15 \pm 1.24$ & $3.79 \pm 0.89$ & 0.2631 \\
\hline Depth involvement & & & & 0.5875 \\
\hline Lamina propria & $7(70)$ & $27(67.5)$ & $17(56.7)$ & \\
\hline Muscularis mucosa or submucosa & $3(30)$ & $13(32.5)$ & $13(43 \cdot 3)$ & \\
\hline Specimen adequacy & $9(90)$ & $39(97.5)$ & $30(100)$ & 0.2147 \\
\hline Crush artifact & & & & 0.0007 \\
\hline None & $10(100)$ & $38(95 \cdot 5)$ & $17(56.7)$ & \\
\hline Mild & o & $2(5.0)$ & $12(40.0)$ & \\
\hline Moderate & o & O & $1(3 \cdot 3)$ & \\
\hline Severe & 0 & 0 & 0 & \\
\hline
\end{tabular}

Values are presented as mean \pm SD or number (\%). 
performance of biopsy forceps can vary depending on the manufacturing technique of cups, but simple tests such as the glove popping test have been commonly used to assess the performance of biopsy forceps. This is the first study to investigate if there is any difference in performance between the disposable biopsy forceps based on manufacturing techniques and to determine the accuracy of the glove popping test. We showed for the first time that a better result of the glove popping test does not necessarily mean better performance, and that crush artifact, but not specimen size and adequacy, can vary considerably depending on the manufacturing technique of cups.

As mentioned in the introduction section, accessories and endoscopes have had continuous and steady technological advancements. Further development has been restrained by the transition from reusable to disposable accessories. Biopsy forceps are the simplest among endoscopic accessories, with their basic function being specimen obtainment. Therefore, they have advanced in the direction of reducing production cost, rather than technological development. The transition from reusable to disposable biopsy forceps was also a very important issue for manufacturers, and the production cost could not be reduced without considering the performance of biopsy forceps. For this reason, making disposable biopsy forceps in the same way as reusable biopsy forceps, such as the cutting method using precision lathe technique, was highly inefficient in terms of production cost. For this reason, there was only one company that manufactured cutting forceps. Consequently, pressing and molding forceps were introduced sequentially to continue the effort to reduce the production costs. Many third-party companies and major companies in Korea continue to develop new disposable biopsy forceps, but most of them focus on lowpriced molding forceps. The reality is that the emphasis is predominantly placed on the user's convenience and the design of the handle rather than the performance of cups. Although some institutions are using the glove popping test to assess the biopsy forceps objectively, the actual association between this test and the performance of forceps has not been reported yet.

The problem of the glove popping test, as mentioned earlier, is that the test result can be good not only when cutting is done accurately with good performance (Fig.
2B) but also when the glove is torn due to the coarse surface of the cups (Fig. 2C). As can be seen in Table 2, which shows the results of the glove popping test, the results of the molding forceps were generally good. However, these results bear little similarity when compared with the results of performance shown in Tables 3 and 4 . The assumption that the tearing phenomenon by rough surface of cups would be the mechanism of glove popping by the molding forceps can be made based on the fact that crush artifact was more frequent than in the other groups. However, because of the very high popping rate in type D forceps, there was a significant bias that increased the popping rate of the entire molding forceps. Nevertheless, we think that evaluating the performance of biopsy forceps using the popping test is not accurate because we did not find any differences between the groups. We would like to argue that using the glove popping test alone is not recommended when assessing the performance of biopsy forceps.

Crush artifact, which does not occur when the specimen grasped inside the cups cuts cleanly, refers to a serious compression in the middle part when some of the tissues outside the cups are torn apart because of poor grip ability. As can be seen in Fig. 4, crush artifact can be graded depending on the extent of base tissue, which has not been grasped but has been pulled out without being cut cleanly from the tissue. A severe grade means that the compression is serious enough to affect the diagnosis [5]. As shown in Table 4, fortunately, none of the three groups had severe crush artifacts, but crush artifacts were most common with the molding forceps. This means that during an endoscopic biopsy, complications may occur depending on the type of biopsy forceps used and the condition of the base tissue. This also implies that when performing biopsy of deep ulcer or relatively thin duodenum or colon, the specimen may not cut cleanly and some of the base tissue can be torn, causing complications, such as bleeding or perforation. A previous report that only compared pressing forceps also reported a $6 \%$ to $7 \%$ incidence of crush artifact, which was similar to our results [5]. This report also explained that little crush artifact means lack of tissue compression with a good tissue fenestration due to good grip ability of the cups.

The limitations of this study are as follows: (1) in vitro and in vivo animal study; (2) small sample size of biopsy 
specimens per type of biopsy forceps; (3) performed gastric biopsies only; (4) assessing performance simply according to the manufacturing techniques of cups, given that other parts of biopsy forceps can also affect the performance; (5) lack of subtype analysis because not many types of cups were used; (6) lack of analysis of biopsy-induced performance complications such as immediate bleeding; and (7) the adequacy of biopsy specimen and crush artifact may depend on the pulling force of the endoscopist. The participation of two or more endoscopists is recommended for a well-designed future study.

In conclusion, this was the first study to compare the performance of biopsy forceps according to manufacturing techniques. We found that the molding forceps provided lower performance than the cutting and pressing forceps in terms of crush artifact. In addition, the simple glove popping test should not be recommended for the evaluation of performance of biopsy forceps.

\section{KEY MESSAGE}

1. The performance of disposable biopsy forceps can vary depending on the manufacturing technique for their cups.

2. The glove popping test, commonly used to assess the performance of biopsy forceps, does not represent the exact performance.

3. In terms of crush artifact, the molding forceps provided lower performance than the cutting and pressing forceps.

\section{Conflict of interest}

Jong Pil Moon and Ho Yun are research workers at the Interventional Research Center of M.I.Tech Co. Ltd. which is developing products related to the research being reported. The others have no financial conflicts of interest.

\section{Acknowledgments}

Chang-Il Kwon received research support for this study from the Industry \& Energy and the National Center of Efficacy Evaluation for the Development of Health Products Targeting Digestive Disorders (NCEED).

\section{REFERENCES}

1. Tytgat GN, Ignacio JG. Technicalities of endoscopic biopsy. Endoscopy 1995;27:683-688.

2. Kaneko E, Kumagai J, Honda N, Nakamura S, Kino I. Evaluation of the new giant-biopsy forceps in the diagnosis of mucosal and submucosal gastric lesions. Endoscopy 1983;15:322-326.

3. Ladas SD, Tsamouri M, Kouvidou C, Raptis SA. Effect of forceps size and mode of orientation on endoscopic small bowel biopsy evaluation. Gastrointest Endosc 1994;40:51-55.

4. Danesh BJ, Burke M, Newman J, Aylott A, Whitfield P, Cotton PB. Comparison of weight, depth, and diagnostic adequacy of specimens obtained with 16 different biopsy forceps designed for upper gastrointestinal endoscopy. Gut 1985;26:227-231.

5. Sussman DA, Deshpande AR, Shankar U, et al. Comparison of performance characteristics of oval cup forceps versus serrated jaw forceps in gastric biopsy. Dig Dis Sci 2016;61:2338-2343.

6. O'Connor HJ, Axon AT. Gastrointestinal endoscopy: infection and disinfection. Gut 1983;24:1067-1077.

7. Birnie GG, Quigley EM, Clements GB, Follet EA, Watkinson G. Endoscopic transmission of hepatitis B virus. Gut 1983;24:171-174.

8. Fireman Z. Biopsy forceps: reusable or disposable? J Gastroenterol Hepatol 2006;21:1089-1092.

9. U.S. Food and Drug Administration. Enforcement priorities for single-use devices reprocessed by third parties and hospitals [Internet]. Rockville (MD): FDA, 2000 [cited 2018 Jan 3]. Available from: https://www.fda.gov/medicaldevices/deviceregulationandguidance/guidancedocuments/ucmio7164.htm.

10. Alfa MJ, Castillo J. Impact of FDA policy change on the reuse of single-use medical devices in Michigan hospitals. Am J Infect Control 2004;32:337-341.

11. Yang R, Naritoku W, Laine L. Prospective, randomized comparison of disposable and reusable biopsy forceps in gastrointestinal endoscopy. Gastrointest Endosc 1994;40:671-674. 